\title{
Mobilités, transports et santé : argumentaire
}

Sylvanie Godillon et Marie-Soleil Cloutier

\section{OpenEdition \\ Journals}

Édition électronique

URL : http://journals.openedition.org/rfst/676

DOI : $10.4000 /$ rfst.676

ISSN : 2492-3672

Éditeur

Espaces et SOciétés (UMR 6590)

Référence électronique

Sylvanie Godillon et Marie-Soleil Cloutier, « Mobilités, transports et santé : argumentaire », Revue

francophone sur la santé et les territoires [En ligne], Mobilités Transports et Santé, mis en ligne le 25 mai

2019, consulté le 06 avril 2021. URL : http://journals.openedition.org/rfst/676 ; DOI : https://doi.org/

$10.4000 /$ rfst. 676

Ce document a été généré automatiquement le 6 avril 2021.

\section{cc) (i) \$(}

La Revue francophone sur la santé et les territoires est mise à disposition selon les termes de la Licence Creative Commons Attribution - Pas d'Utilisation Commerciale - Partage dans les Mêmes Conditions 4.0 International. 


\title{
Mobilités, transports et santé : argumentaire
}

\author{
Sylvanie Godillon et Marie-Soleil Cloutier
}

1 Pour ce dossier thématique, nous souhaitons interroger les liens entre la mobilité, les transports et la santé. Les progrès techniques, les avancées numériques, la prise de conscience des impacts négatifs de l'automobile ou encore la valorisation sociale de la mobilité ont récemment renouvelé les enjeux associés à la thématique de la mobilité. Elle gagnerait à être moins abordée sous l'angle techniciste et davantage sous un angle pluridisciplinaire en mobilisant les sciences humaines et sociales, dont la géographie. L'approche populationnelle en santé publique renvoie, entre autres, aux modes de vie et aux environnements physiques et sociaux. Selon cette approche, la mobilité est un facteur à prendre en considération. Le lien entre mobilité et santé est ancien si on considère les influences des médecins sur le développement urbain aux $19^{\mathrm{e}}$ et $20^{\mathrm{e}}$ siècles, avec la réhabilitation des quartiers insalubres. Le bruit et les risques d'accidents liés aux transports sont également étudiés depuis les années 1970. Plus récemment la sédentarité est une thématique analysée sous l'angle du rapport à l'espace. Au cours des deux dernières décennies, les enjeux de pollution de l'air et des émissions de gaz à effet de serre ont renouvelé les approches des relations entre mobilité, transports et santé. Ainsi, des travaux concernent les effets d'une mobilité active sur la santé, d'autres ciblent les nuisances des différents types de transport sur la santé des populations qu'il s'agisse de la sécurité routière ou des effets de la pollution.

2 Dans ce dossier thématique, nous souhaitons décloisonner ces débats pour mettre en regard les différents apports scientifiques dans le domaine des transports, des mobilités et de la santé, selon différentes disciplines (géographie, urbanisme, sociologie, histoire, épidémiologie, etc.) et différentes méthodologies (statistiques, analyse de jeux d'acteurs, diagnostic territorial, analyse de politiques publiques, etc.).

Les articles pourront relever des thèmes suivants (liste non exhaustive) :

- Impacts des transports et de la mobilité sur la santé des populations : Le choix d'un mode de transport a des impacts sur la santé au niveau individuel comme à l'échelle collective. Les transports peuvent avoir des impacts sur la santé en lien avec la pollution atmosphérique, 
l'insécurité routière, le bruit ou l'(in)activité physique. Les recherchesabordant les effets des transports et de la mobilité sur la santé de manière systémique sont attendues, que ces effets soient spécifiques ou globaux. Quelles sont les conséquences sur la sécurité du choix d'un mode de transport? Quel est l'effet global du développement d'une nouvelle offre de transport sur la santé?

- Équité dans le transport et santé : en termes de santé en lien avec les transports, des inégalités sont-elles mesurables selon les catégories de population? Des analyses de publics spécifiques comme les personnes âgées ou les enfants ou des analyses d'usagers des modes de transport sont attendues. Quels sont les liens entre l'accessibilité spatiale à des systèmes de soins et les différenciations observées? Des différenciations sont-elles mesurables selon les espaces? Comment l'environnement et les infrastructures influencent-ils le choix du mode de transport et donc les impacts sur la santé des populations?

- Politiques de transport et santé : Quelles sont les stratégies pour réduire les impacts négatifs des transports sur la santé ? Comment s'articulent les différentes politiques sectorielles? A quelles échelles planifier le transport pour minimiser les effets négatifs sur la santé ? Quelles sont les stratégies de prévention des impacts du transport? Quels sont les arbitrages des pouvoirs publics entre les différents impacts liés au transport? Quelles sont les effets des mesures de planification urbaine sur les transports et la santé?

\section{INDEX}

Mots-clés : transports, mobilités, santé

Keywords : transports, mobility, health

\section{AUTEURS}

SYLVANIE GODILLON

INRS -Centre Urbanisation-Culture-Société, Montréal

MARIE-SOLEIL CLOUTIER

INRS -Centre Urbanisation-Culture-Société, Montréal 